DOI: https://dx.doi.org/10.12795/Temas-Americanistas.2021.i46.03

\title{
EL REPARTIMIENTO DE MERCANCÍAS Y LOS SUBDELEGADOS EN EL ALTO PERÚ. LA DENUNCIA EN 1785 DEL SUBDELEGADO DE CARANGAS, JUAN DIONISIO MARÍN. \\ SUBDELEGATE AND DISTRIBUTION OF COMMODITIES IN ALTO PERÚ. JUAN DIONISIO MARIN”S DENUNCIATION IN 1785, SUBDELEGATEOF CARANGAS.
}

\author{
María Concepción Gavira Márquez. \\ Universidad Michoacana de San Nicolás de Hidalgo \\ ORCID: 0000-0002-0850-8402
}

\begin{abstract}
Resumen:
Este artículo pretende abordar el repartimiento o reparto de mercancías en la región andina, antes y después de la prohibición de este comercio a partir de la aplicación del Régimen de Intendencias. En el virreinato del Río de la Plata, como consecuencia de las sublevaciones de 1780 se suprimió el reparto de mercancías y se aplicó en 1782 el Régimen de Intendencias donde el subdelegado, sustituto del detestado corregidor, tenía la prohibición de realizar esta actividad comercial. Sin embargo, se encuentran muchas evidencias de que los subdelegados continuaron estas prácticas comerciales coactivas, las cuales a veces se permitieron con la justificación del poco aprovechamiento económico que tenían las nuevas autoridades locales. Vamos a estudiar la denuncia interpuesta por los azogueros al subdelegado de Carangas por reparto de mercancías y la defensa de la población indígena en apoyo al subdelegado Marín. Analizaremos las relaciones dentro del partido de Carangas para entender los posicionamientos de los diferentes actores sociales en este proceso.
\end{abstract}

Palabras claves: subdelegados, reparto de mercancías, Carangas.

\begin{abstract}
:
This article concerns the forced distribution(reparto) of commodities in the Andean region before and after the prohibition of this trade, in the viceroyalty of the River Plate, through the introduction in 1782 of the Intendencies following the rebellions of 1780, after which the distribution of commodities was prohibited. This forbade the Subdelegate (who had replaced the detested Corregidor) from engaging in this form of forced commercial activity. However, there is much evidence that the Subdelegates continued these forms of forced trade, which were sometimes justified by pointing to the small economic benefit accruing to local authorities. The article studies the denunciation of the subdelegate of Carangas (Upper Perú) by the miners for distributing commodities, and the defense of the indigenous population in support of the subdelegate Marin. We will analyze the social relations within the province of Carangas in order to understand the points of view of the different social actors in this case.
\end{abstract}

Key words: subdelegates, distribution of commodities, Carangas. 


\section{ISSN 1988-7868}

\section{Introducción}

El reparto de mercancías fue uno de los problemas que más se discutieron durante las últimas décadas del siglo XVIII a partir de las reformas borbónicas ${ }^{1}$ y la implementación del Régimen de Intendencias en los territorios de la América hispana. El "mal gobierno" adjudicado a los corregidores estaba asociado a muchos problemas vinculados con los abusos y la corrupción, responsable en gran medida de las protestas y las sublevaciones indígenas de 1780 en la región andina, especialmente en el Alto Perú. En un intento precipitado por acabar con la detestable figura del corregidor se implementaron las Ordenanzas de Intendentes en 1782 en el virreinato del Río de la Plata, ${ }^{2}$ y a partir de entonces los subdelegados sustituyeron a los corregidores y se produjeron cambios administrativos y jurisdiccionales importantes. Uno de los aspectos en que se puso más atención era acabar con el reparto de mercancías que realizaba el corregidor entre la población indígena por considerarse como una de las prácticas bajo las cuales más abusos y perjuicios se había impartido a los indios. En este trabajo vamos a abordar brevemente en qué consistía el reparto de mercancías, las disposiciones al respecto, las prácticas y la prohibición a las nuevas autoridades, los subdelegados; así como las discusiones sobre sus consecuencias en la economía colonial. Terminaremos con un estudio de caso, la denuncia por reparto de mercancías del subdelegado de Carangas (Alto Perú) Juan Dionisio Marín, el cual fue defendido y apoyado por la población indígena de su partido.

La historiografía sobre los corregidores y el reparto de mercancías en los Andes, está asociada a trabajos clásicos como el de Guillermo Lohman Villena ${ }^{3}$ para el reinado de los Austrias y Alfredo Moreno Cebrián para el periodo borbónico. ${ }^{4}$ Dos obras muy significativas por su gran aportación y por ofrecernos una innumerable cantidad de

\footnotetext{
${ }^{1}$ Sobre el concepto de reformas borbónicas como categoría de análisis, véase Ernest Sánchez Santiró, "Las reformas borbónicas como categoría de análisis en la historiografía institucional, económica y fiscal sobre Nueva España: orígenes, implantación y expansión”. Historia Caribe, vol. 29, (México, 2016), pp. 19-51.

${ }^{2}$ Laura San Martino de Bromi, Constitución indiana de Carlos III. La Real Ordenanza de Intendentes de 1782. (Buenos Aires: Ciudad Argentina, 1999).

${ }^{3}$ Guillermo Lohman Villena, El Corregidor de Indios en el Perú bajo los Austrias. (Madrid: Ediciones Cultura Hispánica, 1957).

${ }^{4}$ Alfredo Moreno Cebrián, El corregidor de indios y la economía peruana en el siglo XVIII. (Madrid: Consejo Superior de Investigaciones Científicas, 1977).
} 


\section{AMERICANISTAS}

\section{ISSN 1988-7868}

\section{María Concepción Gavira Márquez}

El repartimiento de mercancías y los subdelegados en el Alto Perú. La denuncia en 1785 del subdelegado de Carangas, Juan Dionisio Marín. Dossier La vigencia del estudio de los repartimientos en época de subdelegados

referencias documentales admirables que alientan a continuar trabajando sobre el tema. Especialmente destacamos, el estudio de Alfredo Moreno sobre los corregidores en el siglo XVIII, el cual incluye el periodo posterior a la supresión de los corregidores, y aborda la polémica y discusión en torno a la prohibición del repartimiento y las posibles opciones para sustituirlo durante el gobierno de los subdelegados. Como trataremos a continuación, el reparto de mercancías tenía una relación directa con el comercio y la economía americana y también con otras cuestiones ideológicas que se utilizaron para justificarlo, como por ejemplo la incapacidad del indio para acceder a productos en el mercado y la tan aludida "ociosidad del indio". Estas cuestiones levantaron diferentes posiciones y propuestas que también dependieron de la particularidad de las regiones. Estamos haciendo alusión, como abordaremos más adelante a las dos prácticas más difundidas y conocidas como reparto o repartimiento: el reparto de mercancías, o el reparto de dinero a cambio de productos agrícolas o procesados. Estas dos prácticas eran muy diferentes y en palabras del visitador José Antonio Areche la diferencia radicaba: “Ahí [Nueva España] es en compra libre lo que se toma, aquí es en venta forzada del que recibe, lo que se le da". 5

Mientras la historiografía andina es más unánime en plantear el sistema de abuso y coacción relacionado al repartimiento de mercancías en el virreinato del Perú y Río de la Plata, en Nueva España encontramos más diversidad de opiniones, en cuanto que se produjeron prácticas diferentes y se consolidó en una gran parte de la historiografía novohispana la función del alcalde mayor o corregidor $^{6}$ como inversionista que estimulaba la producción regional con sus créditos. ${ }^{7}$ En todo caso, como abordaremos más adelante, la amplitud de la América hispánica es motivo de casuísticas diferentes. En

\footnotetext{
${ }^{5}$ Ibídem, p. 377.

${ }^{6}$ Darío Barriera en su estudio sobre el corregidor de la ciudad de Santa Fe, realiza una introducción sobre las confusiones que generaron entre los historiadores de las instituciones los cargos de corregidor y alcalde mayor. Solorzano decía que en América era el mismo oficio con distinto nombre. Véase Darío Barriera, "Corregidores sin corregimientos: un caso de mestizaje institucional en Santa Fe del Río de la Plata durante los siglos XVII y XVIII”. Revista de Estudios Históricos Jurídicos, vol. XXXVI (Valparaíso, 2014), p. 248.

7 Jeremy Baskes sostiene en su estudio sobre Oaxaca que no hubo coacción y que eran los campesinos de Oaxaca los que solicitaban el crédito o lo aceptaban voluntariamente. Para Baskes la gran mayoría de los repartimientos no implicaba violencia. Jeremy Baskes, "Coerced or Voluntary? The Repartimiento and Market Participaction of Peasant in Late Colonial Oaxaca". Journal of Latin American Studies, vol. 18, 1996.
} 
la Nueva España la dinámica no era uniforme y quizás por eso no generó los conflictos sociales al nivel que se produjeron en la región andina y que terminaron en la sublevación indígena de 1780. Horst Pietschmann hace alusión en Puebla a tres tipos de repartimientos por parte de los corregidores: venta de productos a crédito con pago en metálico, "compra de futuro producto locales con pagos por adelantado igualmente en metálico", y el trueque de unos productos por otros. Estas actividades eran realizadas por los comisionados, generalmente los tenientes y entre los productos repartidos el ganado era el principal. ${ }^{8}$ Recientemente Margarita Menegus, ha realizado un análisis del impacto del repartimiento en las diferentes regiones novohispanas poniendo énfasis en las diferencias de las economías domésticas de las comunidades indígenas, y señala además la variedad en los tipos de repartimientos. Esta autora destaca por ejemplo cómo en los casos de Oaxaca, Yucatán y Chiapas el repartimiento resultó más gravoso para las comunidades. ${ }^{9}$ Es decir, la diversidad en las prácticas en la Nueva España hace complicado las generalizaciones y, en todo caso, el impacto de la coacción puede ser diferente, y aunque el sistema de crédito a cambio de productos pareciera en principio menos abusivo, hay estudios que demuestran que también representaron una práctica coactiva que perjudicaba los intereses de la población indígena. Por ejemplo, este sería el caso de Tehuantepec durante el siglo XVIII, según los testimonios aportados en el trabajo de Laura Machuca. ${ }^{10}$ Tal y como sugiere Menegus, se dieron protestas y levantamientos cuando se produjo una ruptura entre la demanda de las autoridades locales y la capacidad de producción de las comunidades, como ocurrió por ejemplo en Tabasco. ${ }^{11}$ Pero sin duda

\footnotetext{
${ }^{8}$ Horst Pietschmann, "El comercio de repartimiento de los alcaldes mayores y corregidores en la región de Puebla-Tlaxcala en el siglo XVIII". Estudios sobre la Política indigenista española en América, (Valladolid: Universidad de Valladolid, 1977).

${ }_{9}^{9}$ Margarita Menegus, Los pueblos de indios en la Nueva España, siglo XVIII. El impacto de las reformas borbónicas. (México: UNAM, 2020), y "Economía y comunidades indígenas: El efecto de la supresión del sistema de reparto de mercancías en la intendencia de México, 1786-1810”. Mexican Studies/Estudios Mexicanos, vol. 5:2, (Universidad de California, 1989), p. 201-217.

${ }^{10}$ En Tehuantepec los excesos del corregidor y su teniente en 1716 fueron denunciados pues les pagaba la libra de grana a 18 reales cuando en el mercado libre estaba a 24 reales y le exigía arrobas de 30 libras en vez de 25. Laura Machuca, "El impacto del repartimiento de mercancía en la provincia de Tehuantepec durante el siglo XVIII”. Margarita Menegus (coord.), El repartimiento forzoso de mercancías en México, Perú y Filipinas, (México: Instituto de Investigaciones Dr. José María Luis Mora/ UNAM, 2000).

${ }^{11}$ En Tabasco, según Carlos Moreno, los indígenas se quejaron de recibir dos repartimientos al año, "uno para la cosecha y otro para la invernada", y se destacaron por la violencia y la compulsión para realizar los cobros. Las respuestas de la población indígena oscilaron entre la huida y la rebelión, como fue el caso del partido de los Ríos en 1668. Carlos Moreno Amador, Gobernar bajo sospecha: Estrategias del poder y
} 


\section{AMERICANISTAS}

ISSN 1988-7868

\section{María Concepción Gavira Márquez}

El repartimiento de mercancías y los subdelegados en el Alto Perú. La denuncia en 1785 del subdelegado de Carangas, Juan Dionisio Marín. Dossier La vigencia del estudio de los repartimientos en época de subdelegados

consideramos importante destacar lo que señala Sempat Assadourian ${ }^{12}$ y ratifica Menegus, en el virreinato del Perú y del Río de la Plata el impacto del tributo y el repartimiento era mayor cuantitativamente, a lo que se sumaba la obligación de la mita minera en algunas regiones, además de otras cargas, y por tanto el nivel de extracción de los recursos de las comunidades indígenas era mayor y su capacidad de cumplir con estas cargas era más débil y en ciertas coyunturas terminó por manifestarse protestas y levantamientos. ${ }^{13}$

En este trabajo nos vamos a centrar en un caso ubicado en la región andina, en el partido de Carangas, virreinato del Río de la Plata, por lo cual haremos referencia propiamente al corregidor de indios del Perú y pondremos especial atención a la evolución de sus competencias y sus prácticas, entre ellas el reparto de mercancía, el cual fue reglamentado por la Corona en $1751 .{ }^{14}$

Abordar en los Andes el tema del reparto de mercancías y corregidores, nos lleva de forma directa a los abusos sobre la población indígena y las rebeliones de 1780. Moreno Cebrián señala en su trabajo las evidencias de esta relación directa entre los abusos del corregidor en el reparto de mercancías durante las décadas de los 60 y 70 y el levantamiento indígena en la zona andina en 1780-81. A esta línea se sumó con un análisis en profundidad el trabajo de investigación de Jürgen Golte, y aunque se considera reduccionista su tesis de relacionar las mayores cantidades de repartimiento con

prácticas corruptas en la alcaldía mayor de Tabasco (1660-1716). (Sevilla: CSIC/Universidad de Sevilla/Diputación de Sevilla, 2018), p. 240-325.

${ }^{12}$ Carlos Sempat Assadourina aborda en diversos trabajos las diferencias entre el virreinato del Perú y el de Nueva España, véanse de este autor, "La economía colonial: la transferencia del sistema productivo europeo en Nueva España y el Perú". Anuario del IEHS, vol. 9, (Tandil, 1994); y "La despoblación indígena en Perú y Nueva España durante el siglo XVI y la formación de la economía colonial". Historia Mexicana, vol. 38, (México: El Colegio de México, 1989), p. 419-454.

${ }^{13}$ También opina Horst Pietschmann que el sistema de repartimiento era más opresivo en Perú que en la Nueva España. Horst Pietschmann, "El comercio de repartimiento de los alcaldes mayores y corregidores en la región de Puebla-Tlaxcala en el siglo XVIII", p. 148. Margarita Menegus estima un promedio de 12 pesos anuales para la Nueva España y remite a Golte sobre una estimación para el sur de entre 3 y 60 pesos anuales. Margarita Menegus, Los pueblos de indios en la Nueva España, siglo XVIII, p. 261-262.

${ }^{14}$ El análisis del reparto de mercancías y el corregidor en la región andina se ha abordado desde distintos puntos de vista: de forma institucional, en su relación con la economía colonial, y centrándose sobre el impacto en la población indígena y sus repercusiones en las sublevaciones andinas de 1780-81. Esta última línea nos interesa por su importancia en el área del Alto Perú o jurisdicción de la Audiencia de Charcas, entre los autores más importantes vamos a destacar en este texto los trabajos de Jürgen Golte, Sinclair Thomson, Chales Walker, y Sergio Serulnikov. 


\section{AMERICANISTAS}

\section{ISSN 1988-7868}

\section{María Concepción Gavira Márquez}

El repartimiento de mercancías y los subdelegados en el Alto Perú. La denuncia en 1785 del subdelegado de Carangas, Juan Dionisio Marín. Dossier La vigencia del estudio de los repartimientos en época de subdelegados

movimientos de rebelión y protestas, es importante su análisis a la hora de estudiar el reparto de mercancías en la región andina. ${ }^{15}$ Pondremos especial atención en esta coyuntura por su vinculación con la implementación del Régimen de Intendencias de forma precipitada, como ya queda explicado en el estudio de Rafael Diego-Fernández Sotelo, el cual nos demuestra cómo las Ordenanzas del Río de la Plata fueron la adaptación de la propuesta de José Gálvez de 1774 realizada para la Nueva España. ${ }^{16}$

Edberto Oscar Acevedo ${ }^{17}$ publicó un estudio ya clásico sobre la aplicación del Régimen de Intendencias en el Alto Perú poniendo mucha atención en los subdelegados altoperuanos, el cual reconocemos de gran importancia por la magnitud del tema y la cantidad de información que nos ofrece, pero de acuerdo con su opinión consideramos necesario realizar estudios de casos que nos ayuden a evidenciar y analizar mejor las problemáticas y las respuestas ante los cambios operados con la implementación del nuevo régimen. ${ }^{18}$ Otros autores también han abordado las reformas en el virreinato del Río de la Plata, haciendo referencia al ejercicio de los nuevos funcionarios y señalando a los

\footnotetext{
${ }^{15}$ Jürgen Golte, Repartos y Rebeliones. Tupac Amaru y las contradicciones de la economía regional. (Lima: Instituto de Estudios Peruanos, 1980). Se ha criticado la tesis de Golte por considerarla reduccionista a la hora de relacionar el reparto de mercancías con los focos de sublevaciones y protesta de las comunidades indígenas, señalando la importancia de otros factores como la mita (trabajo obligatorio en las minas de Potosí), tributos, diezmos y otras cargas; sin embargo hacemos especialmente alusión a su trabajo porque este trabajo hace énfasis en el estudio del repartimiento, cuantificando los valores y significando las reacciones de la comunidad indígena a partir de mediados del siglo XVIII.

${ }^{16}$ Rafael Diego-Fernández Sotelo, El Proyecto de José de Gálvez de 1774 en las Ordenanzas de Intendentes de Río de la Plata y Nueva España. (Zamora: El Colegio de Michoacán, 2016). Otros estudios sobre las reformas en el virreinato del Río de la Plata y las Ordenanzas de Intendentes han sido realizados por historiadores del derecho argentino: Emilio Ravignani, Ricardo Rees Jones, Eduardo Martiré y José M. Mariluz Urquijo; véase por ejemplo José M. Mariluz, Estudios sobre la Real Ordenanza de Intendentes del Río de la Plata. (Buenos Aires: Instituto de Investigaciones de Historia del Derecho, 1995).

${ }^{17}$ Edberto Oscar Acevedo, Las Intendencias Altoperuanas en el Virreinato del Río de la Plata. (Buenos Aires: Academia de la Historia, 1992).

${ }^{18}$ En la actualidad ya encontramos más estudios sobre los subdelegados para el virreinato del Río de la Plata y también para el virreinato peruano; desde la RERSAB (Red de estudios del Régimen de Subdelegaciones en la América Borbónica) estamos promoviendo el estudio de los subdelegados en toda la América hispana para poder entender mejor la administración a nivel local y los cambios que se operaron a partir de las reformas y la aplicación del sistema de intendencia. Véanse las publicaciones siguientes: Rafael Diego-Fernández, María Pilar Gutiérrez y Luis Alberto Arrioja (Coords.), De reinos y subdelegaciones. Nuevos Escenarios para un nuevo orden en la América Borbónica. (Zamora: El Colegio de Michoacán, Universidad de Guadalajara y El Colegio Mexiquense, 2014); Rafael Diego-Fernández, Graciela Bernal y José Luís Alcauter (Coords.), Subdelegaciones Novohispanas, La jurisdicción como territorio y competencia. (Zamora, El Colegio de Michoacán, Universidad Autónoma de Zacatecas y Universidad de Guanajuato, 2019).
} 


\section{AMERICANISTAS}

\section{ISSN 1988-7868}

\section{María Concepción Gavira Márquez}

El repartimiento de mercancías y los subdelegados en el Alto Perú. La denuncia en 1785 del subdelegado de Carangas, Juan Dionisio Marín. Dossier La vigencia del estudio de los repartimientos en época de subdelegados

subdelegados como los responsables directos de "abusos y corruptelas", ${ }^{19}$ precisamente por carecer de un salario. La escasez de remuneración ha sido vista como argumento para que se involucraran de forma ilegal en el comercio, llegando a manifestarse muchas protestas y denuncias a lo largo de su ejercicio. ${ }^{20}$ David Cahill puso atención en el tema de los repartos de mercancías después de la reforma de Intendentes y señala la dificultad de su estudio por ser una actividad clandestina y, por tanto, difícil de cuantificar. ${ }^{21}$ Pero sin duda, el acercamiento a los archivos nos proporciona evidencias de casos de repartos de mercancías por los subdelegados; estamos seguros que suponen una pequeña proporción de los que debieron producirse, y aunque no podemos generalizar ni precisar sobre la cantidad, las causas y los efectos de estos repartos, como trataremos de analizar en el caso de Carangas, no se pueden ignorar.

En este trabajo nuestra intención será abordar, además de la discusión sobre el repartimiento de mercancías y los efectos negativos a partir de su prohibición sobre la economía regional, el caso específico de la denuncia al primer subdelegado del partido de Carangas por repartimiento de mercancías y estudiar a través de este expediente la posición de los diferentes actores del partido en la investigación realizada por la Audiencia de Charcas, de manera que nos ayude a entender por qué la población indígena fue muy persistente en la defensa y apoyo al subdelegado Marín. Concluiremos intentando contestar una pregunta fundamental a partir de todos estos cambios en las políticas reformistas: ¿Mejoró las condiciones de la población indígena a partir de la supresión del reparto de mercancías? El mismo Francisco de Paula Sanz (superintendente de Buenos Aires) decía que el espíritu de las Ordenanzas de Intendentes era dividir jurisdicciones para contemplar al mismo tiempo una mejor administración de la Real

\footnotetext{
${ }^{19}$ Miguel Luque Talaván, "La Intendencia de Puno: de circunscripción colonial a departamento de la República del Perú (1784-1824)”. Revista Complutense de Historia de América, vol. 25, (Madrid, 1999), p. 228.

${ }^{20}$ Trabajos clásicos sobre las reformas y la aplicación del régimen de Intendencias en el virreinato del Perú y Río de la Plata: Jhon Lynch, Administración colonial española 1782-1810. El Sistema de Intendencia en el virreinato del Río de la Plata. (Buenos Aires: Editorial Eubeda, 1969); Jhon Fisher, El Perú borbónico, 1750-1824. (Lima: IEP, 2000).

${ }^{21}$ David Cahill realiza el análisis de la intendencia de Puno a fines del siglo XVIII, donde se destaparon importantes casos de denuncias por reparto de mercancías de los subdelegados. En Carabaya los repartos de mercancías eran financiados con fondos de la Caja Real y se repartieron mulas, ropa de la tierra, géneros de Castilla, coca, sebo, harina, aguardiente y azúcar. David Cahill, "Repartos ilícitos y familias principales en el sur andino: 1780-1824”. Revista de Indias, vol. XLVIII, n 182-183, (Madrid, 1988).
} 


\section{AMERICANISTAS}

ISSN 1988-7868

\section{María Concepción Gavira Márquez}

El repartimiento de mercancías y los subdelegados en el Alto Perú. La denuncia en 1785 del subdelegado de Carangas, Juan Dionisio Marín. Dossier La vigencia del estudio de los repartimientos en época de subdelegados

Hacienda, establecer una justicia más recta y lograr el beneficio de los indios "que son los que más necesitan la inmediación de un jefe autorizado que vele sobre sus alivios". 22

\section{El corregidor de indios y el reparto de mercancías durante el siglo XVIII}

El corregidor era un oficio que había surgido en Castilla y que adquirió características y competencias diferentes en los territorios americanos, donde se hizo cargo además del gobierno y la justicia, de cuestiones hacendísticas como fue el cobro del tributo indígena ${ }^{23}$. Este tipo de corregidor se encargó del gobierno de las numerosas jurisdicciones conocidas como corregimientos en el virreinato del Perú y que después se convirtieron en partido o subdelegaciones a partir de la aplicación del Régimen de Intendencias.

En el virreinato del Perú y del Río de la Plata el reparto de mercancías entre la población tributaria de los corregimientos era una práctica antigua que la Corona decidió normalizar a mitad del siglo XVIII e intentó controlar a partir de estipular la cantidad y valor de las mercancías que se podían repartir en cada corregimiento. Además esta reglamentación permitía cobrar el impuesto de las alcabalas a los corregidores por ese comercio. Sin embargo, algunas cosas quedaron pendientes de reglamentar, por ejemplo no sabemos si había alguna disposición expresa sobre cuántas veces se realizaba el reparto de mercancías, pues algunos corregidores repartían una sola vez durante su gobierno, el cual consistía en 5 años (designación real) y 2 años (designación del virrey o las audiencias) y otros adquirieron la práctica de hacerlo de forma regular todos los años.

Conseguir un corregimiento era una tarea costosa en dinero y trámites, si el beneficiado era peninsular debía de trasladarse hasta América con los gastos que implicaba, por lo cual llegaba muy necesitado de dinero. Para solucionar estas necesidades los comerciantes acudían en su ayuda con préstamos. La dinámica era la siguiente, los comerciantes, generalmente asentados en Lima o las ciudades más importantes, abastecían al recién llegado de productos para que los vendiera a la población indígena de su corregimiento (repartimiento de mercancías) y también les

\footnotetext{
${ }^{22}$ Citado por Edberto Oscar Acevedo, Las Intendencias Altoperuanas en el Virreinato del Río de la Plata, p. 23.

${ }^{23}$ Lohman Villena, El Corregidor de Indios en el Perú bajo los Austrias.
} 


\section{AMERICANISTAS}

ISSN 1988-7868

\section{María Concepción Gavira Márquez}

El repartimiento de mercancías y los subdelegados en el Alto Perú. La denuncia en 1785 del subdelegado de Carangas, Juan Dionisio Marín. Dossier La vigencia del estudio de los repartimientos en época de subdelegados

facilitaba un préstamo para cubrir sus necesidades en la instalación y pago de fianzas e impuesto relativos al cargo. Todo ello implicaba más deudas y compromisos que el nuevo corregidor tendría que solventar durante el ejercicio de su cargo, para lo cual contaba con un salario y las actividades comerciales que, a pesar de la prohibición en la legislación, les brindaba múltiples ganancias. ${ }^{24}$

El reparto o repartimiento de mercancía realizado por el corregidor y legalizado a partir de 1751, no estaba concebido simplemente como un negocio individual para enriquecer al corregidor, esta carga integraba a una parte importante de la población al mercado. La obligación de conseguir dinero para pagar estas mercancías era reconocida como un estímulo obligado para que la población tributaria se incorporase al mercado ante la necesidad de numerario, bien como mano de obra o vendiendo sus propias mercancías. Esta obligación incorporaba al indio de manera coaccionada al sistema colonial. Este factor de coacción para integrar el indígena al mercado colonial sería una de las cuestiones más discutidas después de prohibir los repartos de mercancías entre los subdelegados. Las consecuencias en el mercado regional fueron analizadas y consideradas, de manera que hubo partidarios de implantar otros métodos para continuar abasteciendo al indio de ciertos productos que habían sido de gran difusión en estos repartos, como fueron las mulas.

El reglamento sobre los aranceles y los productos a repartir para el virreinato del Perú se concretó en 1753 y no tenía como único objetivo reglamentar para evitar los abusos, sino que se pretendía que los corregidores pagaran el impuesto de alcabalas que les correspondía por este comercio. Moreno Cebrián publica la relación donde se especifican las mercancías, cantidad, unidad y precios de todos los corregimientos peruanos. Tomaremos como ejemplo el caso de Carangas, corregimiento del altiplano andino que a partir de 1776 se integraría como todos los de la jurisdicción de la Audiencia de Charcas, al virreinato del Río de la Plata.

\footnotetext{
${ }^{24}$ Moreno Cebrián, El Corregidor, pp. 105-135
} 


\section{ISSN 1988-7868}

TABLA I. Reparto de mercancías en el corregimiento de Carangas.

\begin{tabular}{|l|l|l|l|l|}
\hline Mercancías & Cantidad & Unidad & Precio & Total \\
\hline Mulas & 700 & Una & 25 pesos & 17.500 \\
\hline Ropa de la Tierra & 12.000 & Vara & 7,5 reales & 11.250 \\
\hline Coca & 1.125 & Cesto & 9 pesos & 9.675 \\
\hline $\begin{array}{l}\text { Paño musgo de } \\
\text { Quito y paño azul } \\
\text { de Quito }\end{array}$ & 300 & vara & 7 pesos 4r. & \\
\hline \begin{tabular}{l} 
Hierro \\
\hline $\begin{array}{l}\text { 4.000 pesos con el } \\
50 \% \text { de ganancias } \\
\text { en Ropa de } \\
\text { Castilla }\end{array}$
\end{tabular} & Quintales & 6 pesos 4r. & 100 pesos & 2.000 \\
\hline \begin{tabular}{l} 
Total \\
\hline
\end{tabular}
\end{tabular}

Fuente: Alfredo Moreno Cebrián, 1977, p.328

Las mercancías más importantes eran las mulas y la ropa, según lo especificado en el informe, pero sabemos que la realidad no siempre se atenía a lo reglamentado. Había otros corregimientos donde la ropa tenía estipulado un 100\% de ganancias y entre ellas contaban productos exquisitos como: ruanes, bretañas, medias de seda de mujer y de hombre, listonería de Nápoles. Por supuesto, debemos señalar que a los indios o mestizos no les representaba productos de primera necesidad esos tipos de mercaderías. También entre los productos más frecuentes estaba el hierro, aunque no alcanzaba al más importante, las mulas. Por ejemplo, en el corregimiento de Huarochiri se registraba el reparto de 3.500 mulas al precio de 40 pesos la unidad con un total de 140.000 pesos, o el de Sicasica con 4.000 mulas. ${ }^{25}$ Después de la prohibición del reparto, las regiones que se habían especializado en este tipo de productos sufrieron una importante crisis que tardó en superarse. ${ }^{26}$

\footnotetext{
${ }^{25}$ Moreno Cebrián, El Corregidor, p. 349.

${ }^{26}$ Esto ocurrió especialmente con regiones especializadas en obrajes (ropa de la tierra), mulas o producción de aguardiente, productos que se comerciaban en el reparto del corregidor.
} 


\section{AMERICANISTAS}

\section{ISSN 1988-7868}

\section{María Concepción Gavira Márquez}

El repartimiento de mercancías y los subdelegados en el Alto Perú. La denuncia en 1785 del subdelegado de Carangas, Juan Dionisio Marín. Dossier La vigencia del estudio de los repartimientos en época de subdelegados

Lo estipulado por este reglamento había surgido del dictamen de una junta creada para este propósito, que decidió los productos que "se necesitaba" en cada corregimiento y los precios. Pero esto era un mero discurso. Las mercancías se vendían a un precio sobrevalorado y no eran de primera necesidad. Por ejemplo, en Carangas el reparto de mulas no era bien recibido pues los trajines de los indígenas se hacían con llamas que se criaban en la región, por tanto se veían obligados a malvender las mulas, por las cuales ni siquiera conseguían la mitad del precio que tenían que pagar al corregidor. ${ }^{27}$ Esta misma junta sería la encargada de supervisar y juzgar a los corregidores que no cumpliesen con lo dispuesto en el arancel y el decreto sobre Reglamento de aranceles de Lima con fecha del 20 de diciembre de 1753. En Nueva España esta junta no se reunió hasta $1773 .^{28}$

Entre las competencias de los corregidores se contaban las relacionadas con la actividad minera, ya que fungían como alcaldes o jueces de minas. Los corregimientos con reales de minas eran generalmente muy bien valorados porque eran lugares con recursos, lo cual implicaba para los corregidores más posibilidades en sus negocios porque además del reparto de mercancías se permitían el rescate de plata e incluso ser propietario de minas e ingenios, a pesar de estar prohibido por la legislación.

En los corregimientos y centros mineros como Paria, Oruro, Carangas y Chayanta hubo una participación activa de la población indígena en la sublevación, con una violencia que se manifestó con las muertes del corregidor de Paria $^{29}$, de Carangas ${ }^{30}$ y el de Chayanta ${ }^{31}$, el de Oruro consiguió huir. Estos corregidores tuvieron un ejercicio plagado de abusos y una vinculación con la minería que lo convirtieron en el objetivo

\footnotetext{
${ }^{27}$ Moreno Cebrián, El Corregidor, p. 460.

${ }^{28}$ Ibídem, pp. 360-376.

${ }^{29}$ El corregidor Manuel de la Bodega fue asesinado por los indios sublevados de Paria mientras se empeñaba en cobrar sus mercancías repartidas. Según los indios sublevados, había "hecho tres repartos". Véase Fernando Cajías de la Vega, Oruro 1781: sublevación de indios y Rebelión Criolla, Tomo II. (La Paz: IFEA/IEB/ASDI, 2004).

${ }^{30}$ En 1781 los indígenas sublevados de Carangas mataron al corregidor Mateo Ibáñez y a tres familiares suyos. María Concepción Gavira, Población indígena, Sublevación y Minería. La Caja Real de Carangas y el mineral de Huantajaya. (Arica: IFEA/Universidad de Tarapacá, 2008).

${ }^{31}$ El corregidor Joaquín Alós repartió mercancías por un valor de 109 mil pesos a pesar de estar estipulado en el arancel 92 mil pesos. También sus tenientes Luís Núñez y Lucas Villafañe repartieron mercancías, Tomás Catari denunciaba que el reparto había llegado a los 400 mil pesos. Joaquín Alós tuvo la suerte de ser retirado del corregimiento y pusieron como sustituto a Acuña, el cual fue asesinado mientras llevaba preso a Tomás Catari. Boleslao Lewin, La Rebelión de Tupac Amaru y los orígenes de la emancipación americana. (Buenos Aires: Editorial Hachette, 1957).
} 


\section{ISSN 1988-7868}

perfecto de la venganza de los sublevados. Las siguientes autoridades, los subdelegados también estuvieron implicados en los negocios mineros. En Chayanta, Arizmendi de origen potosino y proveniente de familia de azogueros se involucraba de lleno en el socavón de Colquechaca (Aullagas). ${ }^{32}$ En Paria sabemos que dos de sus subdelegados fueron alcanzados por la justicia ante sus irregularidades. Juan Grandidier que tenía una deuda por tributos fue castigado por la Audiencia de Charcas con multa y destierro y Juan Antonio Mendizabal también tenía una gran deuda por tributos (50.000 pesos) y tenía propiedades mineras que además fomentaba con el caudal de la Real Hacienda. ${ }^{33}$ En Oruro, por ejemplo destacamos a Ramón Moscoso también con deudas en el ramo de tributos y propiedades mineras. ${ }^{34}$ En el partido de Carangas podríamos poner diferentes ejemplos, y del caso de Juan Dionisio Marín nos encargaremos a continuación.

Con la experiencia de haber trabajado diferentes centros mineros altoperuanos, observamos que los subdelegados en los partidos donde había actividad minera, aun a pesar de la prohibición en la legislación, tuvieron en los negocios mineros una fuente de ingresos que encontramos en muy variados testimonios. La mayoría de las deudas de tributos eran invertidas en el rescate de plata o empresas mineras que ofrecían beneficios para mitigar la escasez de recursos de los que se quejaban estos funcionarios. La visita de Diego de la Vega al virreinato del Río de la Plata en 1802 evidenció que la supervisión por el Tribunal de cuentas de Buenos Aires de la contabilidad de las Cajas Reales y las matrículas o revisitas de tributarios estaban en su mayoría muy retrasadas y falta de actualización. ${ }^{35}$ Esta visita al virreinato y los informes enviados por el visitador nos hace cuestionar la eficacia de las reformas en el ámbito fiscal. ${ }^{36}$

\footnotetext{
${ }^{32}$ María Concepción Gavira, Minería en Chayanta. La sublevación indígena y el auge minero 1775-1792. (La Paz: Plural Editores/UMSNH, 2013), Cap. III.

${ }^{33}$ María Concepción Gavira, "Los escándalos de las Cajas Reales"

${ }^{34}$ María Concepción Gavira, "Corregidores versus Subdelegados”, p. 270.

${ }^{35}$ María Concepción Gavira, "El visitador general del virreinato del Río de la Plata Diego de la Vega y las irregularidades en las Cajas Reales Altoperuanas (1802)". América Latina en la Historia Económica, (año 23, 2016), pp. 90-118. Véase el cuadro 1. Algunas Cajas con habían presentado sus libros contables en 50 años, otras no se habían revisado en 10 años.

${ }^{36}$ Klein ha presentado un estudio detallado de los ingresos y los gastos del virreinato del Río de la Plata en 1790 y ha llegado a la conclusión que el disminuido excedente que producía este virreinato escasamente servía para mantenerse a sí mismo. En 1790 se transfirió a la Corona poco más de 100.000 pesos y entre 1790 y 95 hubo años en que no se remitió ningún dinero a la Península. Véase Herbert Klein y N. Dos Santos, "Las finanzas del Virreinato del Río de la Plata en 1790". Desarrollo económico, (vol. 13, 1973),
} 


\section{AMERICANISTAS}

\section{ISSN 1988-7868}

\section{María Concepción Gavira Márquez}

El repartimiento de mercancías y los subdelegados en el Alto Perú. La denuncia en 1785 del subdelegado de Carangas, Juan Dionisio Marín. Dossier La vigencia del estudio de los repartimientos en época de subdelegados

\section{La prohibición del reparto: Discusión y proyectos de socorros}

Moreno Cebrián recoge un gran número de evidencias documentales sobre la responsabilidad de los corregidores y sus abusos en las sublevaciones de 1780 y 81 en el área andina. ${ }^{37}$ Personalidades de todo tipo, autoridades civiles y religiosas, vieron en la tiranía del corregidor y sus abusos en los repartos la causa que abocó a los indígenas a una rebelión violenta que generalmente se consumó en el asesinato del corregidor. Pero estas respuestas no fueron nuevas ni espontáneas, pues ya estaban registrándose en la década de los setenta y las máximas autoridades las conocían. El mismo virrey del Perú relataba en un informe las quejas de los indígenas ante los abusos y las violentas muertes de las autoridades locales (corregidores y tenientes de corregidores) durante la década del 70, y responsabilizaba a la Real Audiencia por la pasividad al "no aplicar remedio, y que los indios ante los resultados y costas de estos procesos tomaron las armas en muchas provincias resueltos a sacudir el yugo" 38

Golte realizó un estudio detallado sobre la relación directa de los abusos en los repartos de mercancías y los focos de las sublevaciones ${ }^{39}$ y aunque esta relación no explique de por sí las sublevaciones de $1780,{ }^{40}$ debemos reconocer que terminaron por fomentar una situación de descontento y desesperación entre la población indígena que

\footnotetext{
p. 369-400; y Herbert Klein, "La economía de la Nueva España, 1680-1809: un análisis a partir de las Cajas Reales". Historia Mexicana, XXXIV, n 49, (México: El Colegio de México,1985), p. 561-609.

${ }^{37}$ Moreno Cebrián, El Corregidor, p. 590.

38 "Expediente General sobre repartimientos a los indios por los corregidores y los excesos y extorsiones que les originaban”. Lima, 1776. Archivo General de Indias (en adelante AGI). Charcas, 692.

${ }^{39}$ Jürgen Golte, Repartos y Rebeliones. Tupac Amaru y las contradicciones de la economía regional.

${ }^{40}$ La historiografía sobre la sublevación indígena en los virreinatos del Perú y Río de la Plata es muy amplia y son muchos los trabajos que han abordado los levantamientos más importantes como el de Tupac Amaru, Tomás Catari y Tupac Catari, así como otros muchos de menor impacto. Aunque algunos autores plantearon que fueron respuesta a las reformas borbónicas, otros estudiosos han señalado la necesidad de conocer los distintos casos para entender los desarrollos particulares, así como la cultura política local. Por ejemplo, Serulnikov ha señalado la desafortunada interpretación Cuzco-céntrica por parte de la historiografía y la necesidad de estudiar los desarrollos regionales en las sublevaciones de 1780-81. En esa línea también encontramos la opinión de León G. Campbell que argumenta que la generalización impide dar respuestas a las preguntas definitivas como las que sugiere plantear la conexión del caso de Oruro y Huarochiri con los parámetros generales del nacionalismo incaico. León Campbell, "Ideología y faccionalismo durante la gran rebelión”, en Steve Stern (comp.), Resistencia y rebelión y conciencia campesina en los Andes. (Lima: IEP, 1990). Charles Walker es de los autores que señala la importancia del estudio de las ideas en los movimientos sociales y la atención a la cultura política local. Charles Walker (comp.), Entre la retórica y la Insurgencia: las ideas y los movimientos sociales en los andes, siglo XVIII. (Cusco: Centro Bartolomé de las Casas, 1996).
} 


\section{AMERICANISTAS}

\section{ISSN 1988-7868}

\section{María Concepción Gavira Márquez}

El repartimiento de mercancías y los subdelegados en el Alto Perú. La denuncia en 1785 del subdelegado de Carangas, Juan Dionisio Marín. Dossier La vigencia del estudio de los repartimientos en época de subdelegados

fracturó los pactos de sumisión con un sistema que no garantizaba las condiciones mínimas de reproducción. Sinclair Thomson señala y analiza cómo el reparto de mercancías tuvo drásticas consecuencias para todo el orden colonial, ya que conllevó la crisis de los cacicazgos porque estos tuvieron un importante papel como intermediarios y representantes de los corregidores. ${ }^{41}$

La inestabilidad y la violencia provocadas por las sublevaciones que se desataron en 1780 y 1781 presionaron a las autoridades, virreyes y visitador, a tomar medidas contundentes y urgentes para poner límites a la extensión de las rebeliones y la violencia. Pocos años antes de este estallido, en las instrucciones que llevaba José Antonio Areche sobre su visita al virreinato peruano en 1777 ya se hacía referencia a este problema y su misión de investigar y considerar la supresión del reparto de mercancías y la posibilidad de aumentar el sueldo de lo corregidores para evitar los abusos de los que se tenían conocimiento. Tanto el virrey como el visitador estaban de acuerdo en suprimir el reparto. Areche presentó un proyecto con el presupuesto de los nuevos salarios que se le pondrían asignar a los corregidores de los virreinatos de Perú y Río de la Plata. ${ }^{42}$ Este proyecto convenció a la Corona y en abril de 1781 una real orden suprimió los repartimientos. ${ }^{43}$ Sin embargo, antes de esa fecha y debido a las tensiones en Cuzco por las acciones de Tupac Amaru, el visitador Areche se precipitó y suprimió el reparto de mercancías a fines de 1780 , unos meses antes de la real orden. ${ }^{44}$

No solo se precipitó la prohibición del reparto, también se implementó de forma urgente el sistema de Intendencias como medida para acabar con la crisis en el área andina y en concreto se aplicó en el virreinato del Río de la Plata en 1782 y después se extendió al del Perú. Este nuevo cuerpo legislativo, que como nos ha demostrado Rafael DiegoFernández ${ }^{45}$ estaba pensado para la Nueva España, era muy claro en lo que respecta a la prohibición del reparto de mercancías, los nuevos cargos de los subdelegados tenían

\footnotetext{
${ }^{41}$ Sinclair Thomson, Cuando solo reinasen los indios. La política aymara en la era de la insurgencia, (La Paz: La muela del diablo/Editorial del THOA, 2006), cap. 4.

${ }^{42}$ Moreno Cebrián, El Corregidor, p. 604.

${ }^{43}$ Ibídem, p. 607.

${ }^{44}$ Ibídem, p. 609.

${ }^{45}$ Rafael Diego-Fernández Sotelo, El Proyecto de José de Gálvez de 1774 en las Ordenanzas de Intendentes de Río de la Plata y Nueva España.
} 


\section{ISSN 1988-7868}

prohibición expresa de realizar ninguna actividad comercial, según el artículo noveno de la Real Ordenanza de Intendentes del Río de la Plata. Pero muy pronto empezaron las contradicciones ante las consecuencias económicas de tal medida y en 1783 una rectificación a ese artículo noveno propuso la conveniencia de prestar a los indios un socorro, el acceso a ciertos productos sin coacción y sobreprecios. ${ }^{46} \mathrm{Sin}$ embargo, se puede cuestionar el impacto de este artículo puesto que dejaba en manos de la Real Hacienda las compras de las mercancías que se podía ofrecer a la población indígena. Todos los proyectos que se propusieron fueron rechazados y no conocemos inversiones por parte de la Real Hacienda para abastecer a la población indígena de estos productos, al menos con evidencias en las Cajas Reales. El intendente de Potosí en sus instrucciones a los subdelegados fechadas en enero de 1784 sobre el comercio de mercancías estipulaba:

$6^{\circ}$... sin excepción no han de poder repartir a los indios, españoles, mestizos y demás castas, efectos, frutos ni ganados alguno...

$7^{\circ}$ Teniendo mandado su Majestad por el artículo 7 de la Real Ordenanza que dé cuenta de Su Real Hacienda se avíe a los naturales y demás necesitados y otras castas que no tengan medios ni proporciones para hacerlo por sí mismo del hierro, aperos, mulas y otros útiles necesarios a la industria y labranza, dándoselos a fiado y a los precios fijos que por solo costo y costas se regulen, dando a estas anticipaciones el nombre de socorros y nunca de repartimientos, me informan los subdelegados los efectos que a este fin sean necesarios en su respectivo partido. ${ }^{47}$

La supresión de los corregidores $^{48}$ en 1783, la pacificación de las regiones sublevadas y la implementación de las intendencias no lograron una recuperación inmediata. La economía del virreinato del Río de la Plata estaba en crisis, las consecuencias inmediatas de la prohibición del repartimiento de mercancías afectó negativamente a dos rubros principales: el mercado regional y el acceso a la mano de obra. Esta última estaba vinculada a la recurrida idea de la ociosidad del indio y su

\footnotetext{
${ }^{46}$ La real Ordenanzas de intendentes fue modificada por Real Cedula del 5 de agosto de 1783 . Se introdujeron 17 declaraciones que procedían de las consultas con distintas autoridades y que fueron aceptadas por José de Gálvez y Carlos III. Laura San Martino, p. 24.

${ }^{47}$ María Concepción Gavira, "Instrucciones para los subdelegados de la Intendencia de Potosí realizadas por el intendente Juan del Pino Manrique en 1784”. Dialogo Andino, (Vol. 42, Iquique, 2013), p. 10.

${ }^{48}$ La supresión se hizo por real cédula del 5 de Agosto de 1783. Véase Alfredo Moreno Cebrián, El Corregidor, p. 631.
} 


\section{AMERICANISTAS}

\section{ISSN 1988-7868}

\section{María Concepción Gavira Márquez}

El repartimiento de mercancías y los subdelegados en el Alto Perú. La denuncia en 1785 del subdelegado de Carangas, Juan Dionisio Marín. Dossier La vigencia del estudio de los repartimientos en época de subdelegados

tendencia a la pereza. El virrey del Río de la Plata en 1784 empezaba con un discurso ya clásico, de cómo los indios "indolentes por naturaleza, dados a la embriaguez" no podrían acceder a los productos necesarios para el desarrollo de la actividad económica, por ejemplo el cultivo de las tierras o el mismo transporte. Se estaba justificando el método de socorro voluntario para solucionar estos problemas. Sin embargo, dentro del virreinato también había cierta oposición a cualquier medida que atentara contra el comercio libre, pues consideraban al indio capaz de acceder a los productos necesarios para su consumo. La opinión generalizada de los intendentes consistió en expresar su negativa al socorro pues serían inmediatos los perjuicios que supondrían la aplicación de cualquier sistema alternativo a los repartos. ${ }^{49} \mathrm{Ni}$ el virrey Loreto, ni el superintendente Francisco de Paula Sanz consideraban el establecer el sistema de socorros porque no le había llegado órdenes de la Corona y porque decían no tener noticas de repartos ilegales por los subdelegados, a pesar de las sospecha de Jorge Escobedo.

Bajo el discurso de la incapacidad del indio para proveerse de lo necesario y su tendencia a la ociosidad, se empezaron a proyectar diferentes medidas de socorros o comercio alternativo que por supuesto levantaron polémica y opiniones encontradas. El mismo visitador Jorge Escobedo, sin negarlo, señalaba que detrás de la idea de un socorro o reparto justo y sin coacción estaba la necesidad de estimular el mercado.${ }^{50}$ En principio, este socorro que se decía debía de estar en manos de la Real Hacienda, en el proyecto de Escobedo estaría bajo el control del Consulado de Lima. La respuesta del Rey fue contundentemente negativa.

La falta de mano de obra también era contemplada como una consecuencia inmediata de la supresión del reparto de mercancías, especialmente en los centros mineros. Las autoridades nuevas no tardaron en quejarse de la falta de mano de obra:

El motivo de la escasez de gente no era otro que la poca de que se compone el partido y que si en tiempos pasados no faltaba gente era porque de la abundante que hay en el de Carangas venían a buscar jornales a la ribera de este, lo que ha cesado desde que se les dejó solo la obligación contribuir el tributo, pues con

\footnotetext{
${ }^{49}$ Ibídem, p. 637.

${ }^{50}$ Hay que reconocer que Escobedo al menos no utilizó el discurso que era "por el bien del indio", ante la incapacidad de cuidar por sus intereses. Su intención fue manifestada de forma muy clara y el objetivo principal estaba destinado a estimular el mercado.
} 


\section{ISSN 1988-7868}

buscar cinco pesos, siete no nueve pesos según la tasa de él, se echan a la haraganería a que son muy propensos y no quieren trabajar porque en buscándose para dicho tributo, su coca y un poco de maíz nada necesitan más, según sus pensamientos, para vivir. ${ }^{51}$

La menor necesidad del indio de conseguir dinero para el pago de sus obligaciones con el sistema colonial les permitía una mayor libertad. La coacción que significaban las cargas sobre la población tributaria representaba una garantía de fuerza de trabajo especialmente en los centros mineros, donde los azogueros siempre andaban quejándose de la falta de trabajadores para las minas e ingenios. A diferencia de Nueva España, donde a los trabajadores mineros se les recompensaba con la excepción del tributo como forma de estimular el trabajo minero, ${ }^{52}$ en los virreinatos del Perú y Río de la Plata la población tributaria debía seguir contribuyendo con su tasa además de la necesidad de conseguir dinero para pagar los repartos de mercancías de los corregidores. En la mayor parte de los centros mineros andinos la mano de obra era indígena. A veces, esta mano de obra era estacional y tan solo se empleaba hasta conseguir el dinero necesario para el pago de esas tasas: tributo y reparto. Al suprimirse esta última, el indio tenía una menor necesidad de emplearse y se podía permitir el lujo de mantenerse con sus tierras, ganados y trajines habituales ¿Y cuánto podría representar esa disminución? Hay variedad de casos, pero por ejemplo los indios se quejaban en el corregimiento de Carangas que a veces llegaban a pagar hasta 100 pesos al año por cuestiones de reparto. ${ }^{53}$

Los afectados por la supresión del reparto de mercancías no eran solo los comerciantes o los productores de esas mercancías o los criadores de mulas, también los mineros y azogueros manifestaron sus problemas de falta de mano de obra que en esos momentos era más escasa con la disminución de las tasas que obligaban al indio a emplearse en las labores mineras. Se manifestaron muchos agraviados como

\footnotetext{
${ }^{51}$ Carta del subdelegado de Oruro, Simón Romano a la Audiencia de Charcas. Oruro, 9 de octubre de 1792. Archivo Nacional de Bolivia (en adelante ANB), Minas, T. 131, $\mathrm{N}^{\circ} 13$.

52 Véase Isabel M. Povea, "Conflictos y negociaciones. La defensa de los arreglos laborales tradicionales por parte de los trabajadores mineros de Nueva España, segunda mitad del siglo XVIII". Tiempos Modernos, vol. 37, (Madrid, 2018/2), p. 234-257.

${ }^{53}$ María Concepción Gavira, "La población del corregimiento de Carangas (virreinato del Río de la Plata) a fines del siglo XVIII". América Latina en la Historia Económica; n³3, (México, 2010), p. 65-90.
} 


\section{AMERICANISTAS}

\section{ISSN 1988-7868}

\section{María Concepción Gavira Márquez}

El repartimiento de mercancías y los subdelegados en el Alto Perú. La denuncia en 1785 del subdelegado de Carangas, Juan Dionisio Marín. Dossier La vigencia del estudio de los repartimientos en época de subdelegados

consecuencia de los nuevos cambios. Era normal que hubiera polémica, protestas y nuevas propuestas para aliviar la gravedad de la situación que se presentaba.

Hubo otros proyectos como el de José de Lagos, el de Antonio Boza, también desde el virreinato del Perú. ${ }^{54}$ En definitiva, se pretendían conjugar los intereses de todos sin agraviar al indio, al cual no se le consultaba. Debemos señalar que entre las autoridades había diferentes opiniones casi todas buscando salvar los intereses de los distintos actores que se beneficiaban del trabajo del indio, y sin embargo algunas de estas autoridades no se dejaron convencer por el discurso de que el indio era incapaz de acudir al libre mercado a realizar sus compras. Pero sobre todo, en la región andina influyó de manera importante el miedo al indio. Las amenazas ante cualquier conato de rebelión eran temidas y causaban impacto. Por ejemplo, en Chayanta hubo un conato de rebelión en 1795 ante el intento de ampliar el número de mitayos y el virrey suprimió la ejecución. El intendente de Potosí y el subdelegado de Chayanta no pudieron ejecutar esta ampliación de los mitayos a pesar de tener permiso de la Corona ante la amenaza de una nueva sublevación por "la nueva mita". ${ }^{55}$ Después de la violencia desatada durante los años 1780-1783, el miedo al indio, a la "plebe", por parte de las elites y autoridades coloniales, como dice Scarlett O’Phelan perduró hasta el siglo XIX. ${ }^{56}$

A fines del siglo XVIII, las denuncias de subdelegados, tanto del Perú como del Río de la Plata, que practicaban reparto de mercancías eran frecuentes y más numerosas de lo proyectado por los reformistas. Uno de los argumentos que las justificaba fue que el subdelegado tenía una corta remuneración y que dependía de la recaudación del tributo de los partidos, los cuales presentaban distintas condiciones en cuanto a población. Por ejemplo, el salario del corregidor de Carangas era de 1.562 pesos y era considerado como "buen” corregimiento, según algunas calificaciones del siglo XVIII. Esta apreciación dependía de la población y los recursos, factores importantes para conseguir beneficios del ejercicio del cargo, en este caso la explotación de las minas conllevaba beneficios

\footnotetext{
${ }^{54}$ Moreno Cebrián, El Corregidor, p. 659.

${ }^{55}$ Gavira, Minería en Chayanta. La sublevación indígena y el auge minero, 1775-1792. (La Paz: Plural/UMSNH, 2013), p. 105.

${ }^{56}$ Scarlett O’Phelan, “La construcción del miedo a la plebe en el siglo XVIII a través de las rebeliones sociales”. Claudia Rosas Lauro (coord.) El miedo en el Perú, siglo XVI-XX, (Lima: Universidad Católica del Perú, 2005) pp. 123-37.
} 


\section{AMERICANISTAS}

\section{ISSN 1988-7868}

\section{María Concepción Gavira Márquez}

El repartimiento de mercancías y los subdelegados en el Alto Perú. La denuncia en 1785 del subdelegado de Carangas, Juan Dionisio Marín. Dossier La vigencia del estudio de los repartimientos en época de subdelegados

interesantes. Si la población contaba con recursos podría pagar mejor las mercancías repartidas. Además, en los distritos mineros el corregidor era alcalde o juez de minas y aunque la participación en los negocios y beneficios mineros estaba prohibido por la ley, ${ }^{57}$ son generalizadas las evidencias sobre sus intervenciones. A partir de 1784, el nuevo subdelegado en Carangas pasaba a cobrar según la nueva legislación un premio de 4\% del monto de tributos. ${ }^{58} \mathrm{El}$ aliciente y atractivo para ejercer este cargo dependía de la cantidad de población de los partidos o subdelegaciones y del monto de la tributación estipulada, de la cual el $4 \%$ se quedaba el subdelegado, pero esta cantidad se reducía porque tenía que separar el $1 \%$ para el cobrador. ${ }^{59}$ Es decir, el subdelegado de Carangas cobraba en función de la matrícula tributaria, la cual tuvo sus variaciones por las revisitas $^{60}$ efectuadas desde 1784 a 1825. En 1784 el subdelegado Juan Dionisio Marín cobraba el $3 \%(4 \%-1 \%)$ de 21.677, es decir 650 pesos aproximadamente. No tenemos datos de otros ingresos como el cobro por las costas judiciales, pero debemos considerar que el corregimiento de Carangas no representaba una región con muchas posibilidades durante las últimas décadas del periodo colonial, pues la actividad más interesante, la minería, se encontraba en crisis. Según un informe de 1784, los españoles residentes en el partido no superaban el número de seis y algunos mestizos, los cuales no sobrepasaban de cincuenta. Según declaraciones del subdelegado Marín, durante su gestión no había cobrado aranceles por "no haber alli materia sobre que exigir derechos". ${ }^{61}$ No queremos

\footnotetext{
${ }^{57}$ Recopilación de las Leyes de Indias, 1681. Libro IV, título 21 y 22, "Que los alcaldes mayores de minas no compren ni rescaten plata", "Que ningún alcalde mayor, juez, ni escribano de minas tenga compañía con dueños de minas, ni las descubra".

58 Victor Gayol considera que no podemos denominar a esta remuneración como salario fijo y especialmente en el caso del subdelegado, lo cual representaba un premio por su ejercicio, que además podría variar según las matrículas realizadas en las diferentes revisitas para la actualización del tributo, frecuentes a fines del siglo XVIII y principios del siglo XIX, y de la capacidad de cobro de los recaudadores. Véase Victor Gayol "Retribución de los subdelegados en la Nueva España. Acercamiento preliminar al estudio de los derechos de judicatura". Rafael Diego-Fernández Sotelo et al. (coords.) De Reinos y subdelegaciones. Nuevos Escenarios para un nuevo orden en la América Borbónica. (Zamora: el Colegio de Michoacán, 2014), pp. 49-69.

${ }^{59}$ En Nueva España esta cantidad era superior: $5 \%$ que se reducía al $4 \%$ después de pagar al recaudador.

${ }^{60}$ Las diferentes matrículas tributarias que resultaron de las revisitas de fines del siglo XVIII muestran una recuperación demográfica muy poco significativa, pero debemos considerar el empobrecimiento de Carangas y las estrategias fiscales de la población tributaria que en algunos lugares pasó de la condición de originario a la de forasteros. Véase María Concepción Gavira, "La población del corregimiento de Carangas".

${ }^{61}$ Declaración de Juan Dionisio Marín, La Plata 6 de marzo de 1787. ANB, Minas, T. 96, n 20, f. 105 v. El subdelegado dijo que no encontró los aranceles que debería cobrar y le preguntaron que si no encontró en el archivo esta información, por qué no preguntó al intendente. Decía que el motivo era que allí no había
} 


\section{AMERICANISTAS}

\section{ISSN 1988-7868}

\section{María Concepción Gavira Márquez}

El repartimiento de mercancías y los subdelegados en el Alto Perú. La denuncia en 1785 del subdelegado de Carangas, Juan Dionisio Marín. Dossier La vigencia del estudio de los repartimientos en época de subdelegados

entrar en discusión sobre si era buena o mala la remuneración del subdelegado, pero en todo caso era menor de la cobrada por el corregidor, sin además contar con los beneficios del reparto de mercancías.

En definitiva, debemos considerar muchas y diferentes condiciones que debemos de tener en cuenta para evaluar qué tan suficiente estaba remunerado el ejercicio de los subdelegados, en todo caso en la región andina no respondía a las expectativas de los posibles postulantes. Esto se manifestaba en la dificultad de encontrar quienes estuvieran dispuestos aceptar, según decían los intendentes, ejercer este cargo en estas condiciones, máxime cuando se pretendía que el subdelegado no fuera originario o vecino del partido donde debía ejercer. Fueron frecuentes las quejas de los subdelegados por los gastos que tenían que afrontar y los escasos ingresos que tenían. Por ejemplo, el subdelegado del partido de la Puna (Intendencia de Salta) Juan Bautista Villegas pedía que se le aumentara la remuneración pues no podía mantenerse en su cargo: "repetidas veces he ocurrido a ese gobierno representando sumisamente los perjuicios que me ocasionan el ejercicio de mi empleo que no me da con que subsistir ni me deja arbitrio de buscarlo para mi crecida familia". ${ }^{62}$ Pero no debemos dejarnos engañar por su discurso, pues este subdelegado tenía propiedades y negocios mineros en Cochinoca (Salta), lo cual produjo quejas y denuncias de los vecinos de estos asientos de minas porque el subdelegado abusaba de sus competencias y se quedaba con las mejores minas. ${ }^{63} \mathrm{El}$ intendente de Cochabamba Viedman decía que "aun en la misma provincia son poco los sujetos acomodados a quien poder echar mano"; 64 es decir, los requisitos que se exigían y las condiciones que se ofrecían eran una gran limitante. Los problemas que conllevaron esta remuneración o

\footnotetext{
necesidad por no haber asuntos, ni pleitos. Sin embargo, reconoce que por algunos trámites cobró algunos reales y por otros le llevaban "cuatro o seis huevos".

${ }^{62}$ María Florencia Becerra y Dolores Estruch, "No soy un juez de farsa expuesto a la inclemencia de todos los provincianos: Minería y conflictos jurisdiccionales en torno al subdelegado del partido de la Puna, Jujuy a finales del siglo XVIII", en Cuadernos del Instituto nacional de Antropología y Pensamiento latinoamericano, $\mathrm{n}^{\circ}$ 3, vol. 1, (Buenos Aires, año 2016). El subdelegado de la Puna Villegas fue subdelegado posteriormente de Paria donde tuvo una causa abierta por la falta de entrega del tributo. Su deuda ascendía a 5.190 pesos. María Concepción Gavira, "Corregidores versus Subdelegados", en Rafael Diego-Fernández Sotelo et al. (coords.) De Reinos y subdelegaciones. Nuevos Escenarios para un nuevo orden en la América Borbónica. (Zamora: el Colegio de Michoacán, 2014). p. 273.

${ }^{63}$ Según Becerra y Estruch, se produjeron denuncias de los vecinos por numerosos abusos, en concreto porque se quedó con minas que puso a nombre de su hijo José Fausto Villegas y de su cuñado don José Pizarro. Véase "No soy un juez de farsa", p.71.

${ }^{64}$ Acevedo, Las Intendencias, p. 113.
} 


\section{ISSN 1988-7868}

premio, tan limitado en algunas ocasiones, fue un pendiente que se discutió y se intentó solucionar estableciendo sueldos. La Ordenanza de 1803 tenía regulado distintas categorías de subdelegados y sueldos, pero esta no se llegó a aprobar y el problema continuó vigente. ${ }^{65}$

Simultaneo a los diferentes proyectos sobre la idoneidad de los socorros o permisos para comerciar, o también sobre el establecimiento de sueldos, la realidad se impuso y desde muy pronto se produjeron denuncias y quejas por los repartos que realizaban los subdelegados en la jurisdicción de la Audiencia de Charcas. Son numerosos los testimonios sobre subdelegados que no entregaban el total del tributo y los que se dedicaban a comerciar. Al mismo virrey Marqués del Loreto le llegaron anónimos denunciando los frecuentes abusos de los subdelegados que buscaban negocios para conseguir beneficios:

que en algunas provincias o se trabajaban minas o se comercia a beneficio de sus jefes; que en otras se ha procedido casi a un formal repartimiento, pagándose las mulas con el mismo dinero atesorado en las cajas, que se benefician las subdelegaciones y que los subdelegados reparten para indemnizarse ${ }^{66}$

Los mismos intendentes reconocían las actividades comerciales de algunos de los subdelegados de su jurisdicción e incluso los disculpaban. El intendente de Potosí decía en Tarija haber nombrado a Manuel de Molina, "europeo y dedicado al comercio, sin lo que no podría ejercer aquella judicatura, que creo solo le valga ciento cincuenta pesos". 67

La posible solución que representaba la adjudicación de un sueldo no se pudo aplicar, por tanto queda pendiente saber si con esa medida se hubiera solucionado o reducido el problema del reparto de mercancías o negocios ilegales. La Ordenanza General de Intendentes de 1803 no fueron aprobada y quedaron pendientes muchos asuntos que podrían haber mejorado a partir de la nueva legislación. Especialmente el

\footnotetext{
${ }^{65}$ Ricardo Rees Jones, "La Ordenanza General de Intendentes de 1803”, p. 181. Para el virreinato del Río de la Plata se establecerían 13 subdelegaciones de primera clase cobrando 2.400 pesos anuales, 21 de segunda con 1.800, y las restantes de tercera cobrando 1.200 pesos.

${ }^{66}$ Citado por Acevedo, Las Intendencias, p. 213.

${ }^{67}$ Ibídem, p. 215.
} 


\section{AMERICANISTAS}

ISSN 1988-7868

\section{María Concepción Gavira Márquez}

El repartimiento de mercancías y los subdelegados en el Alto Perú. La denuncia en 1785 del subdelegado de Carangas, Juan Dionisio Marín. Dossier La vigencia del estudio de los repartimientos en época de subdelegados

anexo de estas Ordenanzas contenía unas instrucciones para los subdelegados que consistían en 34 artículos que detallaban sus competencias. ${ }^{68}$

\section{La denuncia del subdelegado de Carangas por repartos ilegales}

El corregimiento de Carangas, con una población mayoritariamente indígena conformada por aymaras y un reducido número de urus, se encuentra en la región occidental del altiplano andino, en la actual Bolivia, lindando con los valles de la costa pacífica. El proceso de colonización concentró la población en distintas reducciones o pueblos: Huachacalla, Andamarca, Corque, Choquecota, Hayllamarca, Totora, Curaguara, y Turco; ${ }^{69}$ aunque a fines del siglo XVIII el subdelegado decía que la población estaba muy dispersa y que estos pueblos se encontraban vacíos. ${ }^{70}$ Los indígenas se dedicaban a la cría de llamas y alpacas, al pastoreo e intercambio de productos entre la puna, el valle y la costa, los carangas eran reconocidos por ser buenos trajinantes ${ }^{71} \mathrm{y}$, en menor medida, también se dedicaban a la minería, bien como trabajadores o bien por su cuenta recogiendo mineral en minas abandonadas.

Esta región no tenía mucho atractivo para la población española a no ser por el descubrimiento y explotación de minas de plata a principios del siglo XVII. ${ }^{72}$ En 1652 se instaló la Caja Real en el pueblo de Curaguara o también conocido como Espíritu Santo de Carangas, con el fin de controlar la producción de plata y evitar el contrabando. ${ }^{73} \mathrm{~A}$ partir de entonces, las autoridades coloniales, oficiales reales, corregidores, y subdelegados a pesar de las prohibiciones negociaron con la plata, invirtiendo en minas e ingenios, rescatando, negociando con el abastecimiento de azogue, e incluso subvencionando con el capital de la real hacienda las propias inversiones mineras. ${ }^{74}$

\footnotetext{
${ }^{68}$ Ricardo Rees, "La Ordenanza”, p. 181.

${ }^{69}$ Gille Riviere, "Sabaya: Structures socioéconomiques et representations symboliques dans le Carangas, Bolivie”. Tesis de doctorado inédita. Ecole de Hautes Etudes en Sciences Sociales, París, 1982.

${ }^{70}$ Informe del subdelegado de Carangas, 1784. ANB, Minas, T. 96, $\mathrm{n}^{\circ} 17$.

${ }^{71}$ Ximena Medinaceli, Sariri, los llameros y la construcción de la sociedad colonial. (La Paz: IFEA/Plural, ASDI/IEB, 1999.

${ }^{72}$ Alonso Barba, El arte de los metales en que se enseña el verdadero beneficio de los de oro y plata por azogue, 1640. (Valencia: Editorial París,1993).

73 "Cartas del virrey conde de Salvatierra. Año 1652”. AGI, Lima, 56. El virrey advertía que el corregidor de Arica era minero de Carangas, "gran mercader que tiene un yerno con dos navíos en esta mar..." y era conocido que practicaban el contrabando de plata.

${ }^{74}$ Gavira, Población indígena.
} 


\section{ISSN 1988-7868}

Una de las cargas más pesadas para los tributarios era el reparto de mercancías que realizaba el corregidor. El reglamento o arancel estipulado le permitía al corregidor de Carangas un reparto por valor de 54.525 pesos, pero a principios de los sesenta se aumentó hasta 79.225 pesos. Sin embargo, los caciques de los pueblos de Carangas no se quedaron pasivos y denunciaron en 1762 los abusos del corregidor Joaquín Areizaga que había repartido mulas a 32 pesos cuando el precio estipulado en el arancel era de 25 pesos. Según la información de los caciques, el precio de la mercancía repartida se pagaba la mitad en seis meses y la otra mitad cuando se cumplía el año.

El fiscal de la Audiencia de Charcas le requirió al corregidor que se limitara al precio establecido en el arancel o mostrara el permiso para vender las mulas a ese precio superior. El corregidor decía tener permiso del virrey. Estas décadas comprendidas entre 1754 y 1780, se distinguieron según el estudio de Golte, por grandes abusos en el reparto, de manera que en muchos casos se triplicó el volumen de lo establecido legalmente. ${ }^{75} \mathrm{La}$ respuesta de la Audiencia de Charcas fue consultar con el virrey y en la resolución final se volvió a la cantidad establecida en un principio sobre el valor de productos a repartir. De todos modos, durante la sublevación de 1781 el corregidor fue ajusticiado por los indígenas sublevados y a través del tesorero se quejaron: "que los corregidores con sus excesivos repartimiento les exigen cada año a cada uno de los indios setenta y cien pesos en efectos que no necesitan". ${ }^{76}$ Esto nos hace pensar que no acabaron los abusos a pesar de lo resuelto por la Audiencia de Charcas, como además comprobamos en las referencias a las extorsiones del anterior corregidor Antonio Zorrilla. ${ }^{77}$

Después de la muerte del corregidor Ibáñez a manos de los sublevados nombraron a Antolín Chavarri como corregidor provisional con la prohibición de efectuar repartos de mercancías mientras designaba un nuevo subdelegado. El primer subdelegado fue Juan Dionisio Marín que llegó a Carangas en julio de 1784 y, muy poco tiempo después, a principios de 1785 fue denunciado ante la Audiencia de Charcas por rescatar mineral. Los dos azogueros que lo denunciaron decían que repartía dinero entre los indígenas los cuales

\footnotetext{
75 Golte, Repartos y Rebeliones, 1980, p. 117.

${ }^{76}$ El tesorero de la Caja Real de Carangas al intendente de Buenos Aires, Carangas, 7 de febrero de 1781. AGI, Charcas, 706, Exp. 480.

77 “Expediente General sobre Repartimientos...” Lima, 1776. AGI, Charcas, 592.
} 


\section{AMERICANISTAS}

\section{ISSN 1988-7868}

\section{María Concepción Gavira Márquez}

El repartimiento de mercancías y los subdelegados en el Alto Perú. La denuncia en 1785 del subdelegado de Carangas, Juan Dionisio Marín. Dossier La vigencia del estudio de los repartimientos en época de subdelegados

debían devolverles en marcos de plata, a un precio de seis pesos cuatro reales. También se le denunció por reparto de aguardiente. Inmediatamente se le suspendió y retiró de Carangas mientras se realizaba la investigación ante la Audiencia de Charcas. En este proceso destacamos la defensa realizada por los caciques y la población indígena a favor del subdelegado. Sin embargo, a la Audiencia de Charcas y al "nuevo gobierno" no le quedaba otra opción que prestarle la debida importancia a este tipo de denuncia. No se podían permitir nuevos focos de descontento en zonas que habían sido muy activas durante la sublevación indígena, todavía muy presente.

Debemos señalar que no es el único subdelegado implicado en este tipo de actividad comercial "ilegal”, pero sin entrar en la profundidad de los detalles de un pesado expediente vamos a destacar las cuestiones más interesantes del proceso. Nos interesa encontrar respuestas a ciertas cuestiones: ¿Quién denunció al subdelegado y por qué? ¿Había argumentos sólidos en la denuncia? ¿Se comprobó la acusación de reparto? ¿Quiénes lo defendieron y quienes lo acusaban? ¿Conocemos la resolución de la causa?

El subdelegado Juan Dionisio Marín fue denunciado ante la Real Audiencia de Charcas por dos azogueros de Carangas, Manuel Zorrilla y Juan Sigler Campero, es decir no fue denunciado por la población tributaria de Carangas. El porqué de la denuncia de los azogueros, peninsulares montañeses, tiene mucho que ver con la acusación que se le hacía al subdelegado. La "querella" de los azogueros radicaba en que después de sus pérdidas por la sublevación indígena y el gran sacrificio que implicaban las nuevas inversiones en sus instalaciones, se vieron perjudicados por la llegada del subdelegado Marín, el cual "ha venido con el proyecto del rescate de marcos (de plata)".78 Denunciaban al subdelegado de haber repartido dinero entre la población tributaria a cambio de marcos de plata en piña o pasta a un precio de seis pesos cuatro reales, por supuesto transgrediendo las leyes que le prohibían el reparto de mercancías. Pero ¿en qué les perjudicaba esto? Según los azogueros, sus minas eran las únicas en labor en Carangas $\mathrm{y}$ los indios robaban los minerales de sus minas, " $y$ no solamente roban los metales sino

\footnotetext{
${ }^{78}$ Carta al presidente y gobernador intendente de la Audiencia de Charcas. ANB. Minas, T. 96, $\mathrm{n}^{\circ} 20$, fojas 298-300.
} 


\section{ISSN 1988-7868}

que por sacarlos las arruinan destrozando los puentes". ${ }^{79}$ Ante esta situación, decían no tener otra opción que acudir a la justicia y exigir la "justa remoción” del subdelegado. Sugerían que para comprobar el delito del rescate de plata acudieran a los libros contables de la Caja Real de Carangas y comprobasen como el entero del tributo había sido realizado en barras de plata y no en dinero. A esta denuncia se sumó también la del antiguo corregidor de Carangas Antolín Chavarri que acusaba a Marín de malversación con los caudales de la Real Hacienda.

La defensa de Marín argumentó que el dinero empleado en el rescate de plata no era el de los tributos, como decía Chavarri, y que ciertamente pagó los tributos con dinero, salvo un residuo pequeño pagado con una barra de plata porque era un faltante que tuvo que poner de su propio bolsillo. En su defensa, dijo que llegó al partido de Carangas con dinero propio que empleó en el rescate de plata de Huantajaya (Tarapacá) porque en Carangas no había una mina útil. Argumentaba que se había comprobado por el comisionado el mal estado de las minas de los azogueros Zorrilla y Sigler porque las minas de Carangas estaban aguadas, y por lo tanto los jucos (ladrones) no podían extraer metales de sus propiedades. En ese mineral siempre hubo indios jucos y buscones que recogían mineral de minas abandonadas y desmontes y lo vendían a los rescatista. En definitiva, en las características de la denuncia de los azogueros sobre el rescate de plata se advierte un conflicto muy concreto por los recursos del partido. La disputa con los dos azogueros del partido, que habían sido corregidores, ${ }^{80}$ y mantenían mucho poder en Carangas, estaba relacionada con el control de la mano de obra y el rescate de la plata producida por los tributarios en lo que se denomina la minería informal.

La Audiencia de Charcas en 1787 sometió a Juan Dionisio Marín a un interrogatorio, una vez que había dejado el cargo de subdelegado de Carangas. Fueron muy numerosas las preguntas que le hicieron especialmente referente al trato a los indios. Respecto al cobro de aranceles, expresó que no fue habitual porque no había muchos pleitos y que los trámites que hacía a los tributarios se los pagaban con huevos. En sus visitas a los pueblos decía que comía en la casa del cura y si le ofrecieron comida a su

\footnotetext{
${ }^{79}$ Ibídem.

${ }^{80}$ Gavira, Población indígena.
} 


\section{ISSN 1988-7868}

mula fue por voluntad de los caciques. Sobre el reparto de mercancías preguntaron “cuantas fueron las botijas de vino que repartió, entre quienes, a qué precio, bajo qué condiciones y calidades, si de contado o al fiado". ${ }^{81}$ La respuesta fue contundente: "dijo que no ha repartido ninguna botija de vino". Decía que hallándose sin ingreso solicitó traer botijas de vino de la costa para destinarlas a Oruro y Paria, pero que se concentró el arriero en el pueblo de Colque y allí le solicitaron algunos comprar para beber o llevarlas a sus pueblos, y "se vendieron treinta y tantas a diez pesos al contado sin fuerza ni violencia, que esto ni lo tuvo por reparto ni por daño". ${ }^{82}$ Cuando le preguntaron sobre si era cierto que había realizado rescate de plata en Carangas, lo reconoció y se disculpó por el escaso beneficio que le reportaba el 3\% de los tributos "que no llegaría a 500 pesos al año, lo que consideró que no le era suficiente para mantenerse a sí y su familia". Al llegar a Carangas llevaba cinco mil pesos para hacer negocios y compró plata en Tarapacá y algunos marcos en Carangas, "que pagó al rey los derechos de ellos y que en esto jamás juzgó hacer daño ni lo hizo al rey ni al público". A la pregunta sobre los oficios que había ejercido anteriormente, decía Marín que fue justicia mayor de 1774 a 1776 en Lípez y otros oficios sin determinar en Potosí. Representa un ejemplo de los frecuentes casos de personas que habían ejercido de corregidores y después fueron subdelegados.

Al final, no pudieron demostrar el reparto de botijas de vino, las cuales según el subdelegado eran para comerciar en otro partido. Según reconocía Marín, estuvo realizando comercio pero no repartimiento. También recibió como apoyo en su defensa, ciertos escritos y declaraciones de los caciques de diferentes parcialidades en apoyo a su labor como subdelegado, e incluso del cura de Andamarca, el cual admitió haberle prestado una mula al subdelegado. ${ }^{83}$

Tampoco pudo comprobarse la coacción en el recate de plata, por tanto podría entenderse como compra de pasta o piñas de plata de manera libre y voluntaria. En los libros contables de la Caja Real de Carangas se evidencia que en 1785 el subdelegado registró más de mil marcos de plata, pero no se puede comprobar que fueran de Carangas.

\footnotetext{
${ }^{81}$ Declaración de Juan Dionisio Marín fechada en la Plata el 6 de marzo de 1787 (100-112 fojas). ANB, Minas, T. 96, $\mathrm{n}^{\circ} 20$.

${ }^{82} \mathrm{Ibídem,} \mathrm{f.} 106 \mathrm{v}$

${ }^{83}$ Ibídem, Andamarca, 30 de mayo de 1785.
} 


\section{AMERICANISTAS}

\section{ISSN 1988-7868}

\section{María Concepción Gavira Márquez}

El repartimiento de mercancías y los subdelegados en el Alto Perú. La denuncia en 1785 del subdelegado de Carangas, Juan Dionisio Marín. Dossier La vigencia del estudio de los repartimientos en época de subdelegados

En la investigación que se realizó sobre el rescate de plata se presentaron testimonios de trece vecinos del partido, los cuales confirmaron que Marín compraba marcos de plata pero en ningún caso se manifestó que fuera de forma obligada. Los oficiales reales de Carangas también declararon que el subdelegado igual que repartió dinero para la compra de marcos de plata, también repartió botijas de vino, con la disculpa que "él decía que no obligaban a nadie" y excusaban al subdelegado por el escaso beneficio que le reportaba el cargo de subdelegado. En todo caso, sobre lo que se manifiesta más presión durante la investigación era sobre el rescate de plata, centro de la querella de los azogueros agraviados con los negocios del subdelegado.

Pero, ¿por qué encontramos tanta insistencia en la defensa de Marín por parte de los tributarios? ¿Qué cambios importantes supuso la llegada del subdelegado? Los tributarios y especialmente los indios de Todos Santos se mostraron muy pertinaces en la defensa de Marín, pues la llegada del subdelegado posibilitó que recuperaran sus tierras, las cuales habían sido enajenadas por el azoguero Antonio Zorrilla (pariente de Manuel Zorrilla que junto a Sigler denunciaron al subdelegado). No tenemos información de cómo el azoguero se hizo con estas tierras donde vivían los tributarios, pero si tenemos constancias de los abusos que estos azogueros (antiguos corregidores) impartían a los indios haciéndoles trabajar en las minas e ingenios y pagándoles muy mal, a tal punto que "tenía a los chipayas encerrados en un cuarto parte de la noche y a poco que el sol salía, ya los echaba al buitrón" ${ }^{~}$. El alcalde de Todos Santos denunciaba la situación a la que habían sido sometidos por los azogueros-corregidores:

Que nos la comunidad debemos contribuirle cada año alguna cantidad del arriendo de las tierras que poseímos por razón de que en calidad de minero ha comprado de su majestad el ingenio donde reside y todo el territorio del pueblo dicho de Todos Santos. ${ }^{85}$

La mayoría de las autoridades indígenas y tributarios encontraron en el subdelegado un buen aliado para enfrentar a los azogueros, los cuales estaban acostumbrados por haber ejercido como corregidores o tener el beneplácito y la

\footnotetext{
${ }^{84}$ Gavira, Población indígena, cap. 5.

${ }^{85}$ Expediente de los tributarios de Todos Santos. ANB, Minas, T. 96, n 18, f. 15.
} 


\section{AMERICANISTAS}

\section{ISSN 1988-7868}

\section{María Concepción Gavira Márquez}

El repartimiento de mercancías y los subdelegados en el Alto Perú. La denuncia en 1785 del subdelegado de Carangas, Juan Dionisio Marín. Dossier La vigencia del estudio de los repartimientos en época de subdelegados

asociación de estos, a disponer de la población indígena de forma coactiva, impartiendo todo tipo de abusos en el reclutamiento y remuneración de los trabajadores de sus minas e ingenios.

El proceso al subdelegado duró aproximadamente un poco más de dos años. Marín fue denunciado a fines de 1784 y comenzó el procedimiento de la investigación a principios del 1785, de hecho en abril de ese año se ordenaba su destitución mientras se realizaban las pesquisas a cargo de un comisionado. Pero pocos meses después, se anuló la salida del cargo de Marín "porque no se ha podido encontrar persona que acepte la subdelegación de dicho partido de Carangas por haberse excusado el capitán graduado de los reales ejércitos Manuel Allende" ${ }^{86}$ Después de repuesto como subdelegado, Marín solicitó en sucesivas cartas fechadas en septiembre y octubre de 1785 que se aceptara su dimisión por motivos de salud, ${ }^{87}$ sin embargo tardaron más de un año en permitirle salir de Carangas, suponemos por la dificultad de encontrar su reemplazo. En 1786 continuaba esperando el permiso para salir y solicitaba de manera dramática que lo sacasen de "este abismo de Carangas". Para octubre de ese mismo año se encontraba ya en la ciudad de La Plata, donde se le comunicó que permaneciera hasta ser llamado para proceder con el interrogatorio correspondiente a las causas abiertas. ${ }^{88}$ En enero de 1787 se le recibía la declaración a Marín, el cual se decía peninsular nacido en la villa de Luque y tener "más de cincuenta años", era vecino de Cochabamba y había servido dos años como subdelegado de Carangas pero decía que por cuestiones de salud pidió la dimisión. La resolución de la Audiencia de Charcas fue absolver al subdelegado Juan Dionisio Marín e imponer a los azogueros Zorrilla y Sigler "perpetuo silencio". 89

\footnotetext{
${ }^{86}$ Expediente sobre el mineral de Carangas. ANB, Minas, T. 96, $\mathrm{n}^{\circ}$ 20, f. 79-80. El abogado de los azogueros solicita a la Real Audiencia de Charcas la supresión del decreto sobre la reposición de Marín con fecha del 1 de junio de 1785 .

${ }^{87}$ Carta del subdelegado Marín a la Audiencia de Charcas fechada en Carangas a 4 de septiembre de 1785. ANB, Minas, T. 96, $\mathrm{n}^{\circ}$ 20, f. 77-78. El subdelegado solicita por sus malas condiciones de salud le releven en el cargo de subdelegado. El 4 de octubre volvió a enviar otra carta a la Audiencia quejándose de su salud y de la imposibilidad de realizar sus obligaciones.

${ }^{88}$ Carta de Juan Dionisio Marín al presidente de la Audiencia de Charcas fechada en la Plata, 13 de noviembre de 1786. ANB, Minas, T. 96, n 20, f. 92. Marín solicita que ante la comunicación de la Audiencia de su obligación de no dejar la ciudad para responder a una investigación pendiente durante su cargo de subdelegado de Carangas, dejar un abogado para resolver las cuestiones y poder partir a Cochabamba.

${ }^{89}$ Expediente sobre el mineral de Carangas. ANB, Minas, T. 96, n 20, f. 375.
} 


\section{AMERICANISTAS}

\section{ISSN 1988-7868}

\section{María Concepción Gavira Márquez}

El repartimiento de mercancías y los subdelegados en el Alto Perú. La denuncia en 1785 del subdelegado de Carangas, Juan Dionisio Marín. Dossier La vigencia del estudio de los repartimientos en época de subdelegados

\section{Conclusión.}

En 1783, todavía no estaba pacificado totalmente el Alto Perú cuando se había decidido suprimir los corregidores y se había realizado un comunicado expreso para que no se cobrara el reparto de mercancías que quedara pendiente. ${ }^{90}$ Las consecuencias no se hicieron esperar y después de la desolación provocada por la violencia de la sublevación y de la represión, ${ }^{91}$ la reconstrucción no se veía como tarea fácil, la crisis se agravó incluso con una importante sequía. Las amenazas de posibles levantamientos seguían vigentes. Anónimos aparecidos en 1784 y 1785 en muchas ciudades evidencian que la estabilidad y la paz eran muy precarias y que había mucha expectación sobre las reformas y las medidas que prometían acabar con el mal gobierno. ${ }^{92}$ Estos comunicados pidiendo justicia amenazaban con nuevos levantamientos. Consideramos muy significativo el mensaje de los anónimos que exigían castigos por los abusos no sólo para los corregidores, sino también para sus cómplices los tenientes, caciques, alcaldes ordinarios, y administradores de impuestos. La figura del corregidor ha sido muy cuestionada y por tanto protagonista de muchos estudios y mucha atención por parte de la historiografía, pero nos hemos olvidado de "los cómplices", de quienes estuvieron implicados en los abusos y extorsiones, los cuales en muchas ocasiones continuaron en las mismas localidades o en las vecinas con sus mismas funciones. ${ }^{93}$ Los primeros nombramientos de subdelegados en la década de los ochenta, a veces recayeron en las mismas personas que habían ejercido como corregidores, como era el caso de Marín. Por tanto, los efectos de las reformas introducidas con la aplicación del Régimen de Intendencias fueron muy tímidos y lentos. Autores como, Sinclair Thomson, Charles Walker y Sergio Serulnikov conocedores de la región de andina abordan los efectos de esta reforma, destacando la

\footnotetext{
${ }^{90}$ Moreno Cebrián, El Corregidor, p. 596.

${ }^{91}$ La represión fue llevada a cabo por una elite de personajes ilustrados preparados en Academias militares en la Península. Según Juan Marchena, se estima una cifra de cien mil muertos como consecuencia de la represión. Véase de este autor, "Ilustración y represión en el mundo andino 1780-1795. El sangriento camino al corazón de las tinieblas", en Tupac Amaru. La Revolución precursora de la emancipación colonial. (Cusco: Universidad Nacional de Cusco, 2013).

${ }^{92}$ María Concepción Gavira, "La esperanza del Nuevo Gobierno en 1784. Anónimos aparecidos en la Paz”. Historia y Cultura, vol. 41, (La Paz, 2018).

93 Sinclair Thomson señala cómo los corregidores buscaron fortalecer su poder local a partir del nombramiento de muchos tenientes, los cuales tuvieron una gran responsabilidad en el cobro de los repartos de mercancías y por tanto en los excesos y abusos hacia la población indígena. Véase de este autor, Cuando solo reinasen los indios, pp. 129-168.
} 


\section{AMERICANISTAS}

\section{ISSN 1988-7868}

\section{María Concepción Gavira Márquez}

El repartimiento de mercancías y los subdelegados en el Alto Perú. La denuncia en 1785 del subdelegado de Carangas, Juan Dionisio Marín. Dossier La vigencia del estudio de los repartimientos en época de subdelegados

falta de cohesión y coherencia del programa, el cual manifestaba un claro interés en un rubro muy concreto como era el aumentar los ingresos de la Real Hacienda. ${ }^{94}$

La amenaza ante el peligro de nuevas rebeliones indígenas fue muy importante para que, en el virreinato del Río de la Plata, no se establecieran los socorros de forma institucional, como sustitución al sistema de repartos. Sin embargo, muy pronto comenzaron las denuncias formales por las prácticas comerciales ilegales. En 1785 la denuncia al subdelegado de Carangas fue atendida inmediatamente por la Audiencia de Charcas, la cual retiró a Marín del partido mientras se realizaba la investigación, aunque muy pronto lo tuvieron que reponer por no encontrar sustituto. Este es uno de los problemas frecuentes a la hora de encontrar subdelegados para algunos de los partidos del Alto Perú y que tiene mucho que ver con el poco beneficio que reportaba el cargo. La dificultad para encontrar quien ejerciera de subdelegado estaba directamente relacionada con la imposibilidad de conseguir ganancias una vez prohibido el reparto de mercancías. Las autoridades se manifestaron en ocasiones bastante permisivas ante las irregularidades que cometían los subdelegados, según se evidencia en los expedientes que hemos encontrado y las referencias de distintos casos. Sin embargo, a pesar de esta relativa permisibilidad, destacamos la pronta respuesta de la Audiencia de Charcas, que en gran medida respondía al miedo a nuevos tumultos y violencia.

La denuncia en el caso del subdelegado de Carangas provino en principio de dos azogueros del partido, el agravio no había sido a la población tributaria, la cual se vio beneficiada por esta coyuntura y consiguió deshacerse del yugo de estos dos azogueros que durante años habían "tiranizado" a los indios. La población tributaria manifestó su apoyo al subdelegado pues este a través de su negocio de rescate de plata, les daba la posibilidad de no someterse como mano de obra en las minas e ingenios de Sigler y Zorrilla y podían mantenerse de forma independiente buscando sus marcos de plata en las labores abandonadas o desmontes. La población indígena supo negociar mejores

\footnotetext{
${ }^{94}$ Sinclair Thomson señala que en lo que tuvieron éxito las reformas de intendentes fue en la recaudación de tributos. Véase de este autor, Cuando solo reinasen los indios, p.297. Charles Walker, “Civilizar o controlar?: el impacto duradero de las reformas urbanas de los Borbones". Cristóbal Aljovín y Nils Jacobsen (editores), Cultura Política en los Andes (1750-1950). (Lima: IFEA/UNMSM, 2007), p. 117. Sergio Serulkikov, "La imaginación política andina en el siglo XVIII". Aljovín y Jacobsen (editores), Cultura Política en los Andes, p. 383-409.
} 


\section{AMERICANISTAS}

ISSN 1988-7868

\section{María Concepción Gavira Márquez}

El repartimiento de mercancías y los subdelegados en el Alto Perú. La denuncia en 1785 del subdelegado de Carangas, Juan Dionisio Marín. Dossier La vigencia del estudio de los repartimientos en época de subdelegados

condiciones en su relación con las autoridades locales recién llegadas y esto explica el apoyo de los tributarios al subdelegado, el cual consiguió romper las redes de poder que habían permanecido en el corregimiento. Es decir, las comunidades indígenas aprovecharon la coyuntura para negociar mejores condiciones; como señala Serulnikov, ${ }^{95}$ la política borbónica constituyó un recurso político que las comunidades indígenas utilizaron en su propio beneficio. Se restableció la capacidad y posibilidad de pactar por parte de las autoridades indígenas.

Consideramos igualmente interesante destacar de este caso dos aspectos importantes. En primer lugar, la rapidez de reacción de la Audiencia de Charcas con la destitución del subdelegado de Carangas, y en segundo lugar la absolución de Marín, ya que la investigación no pudo demostrar que se tratase de un "reparto", porque no se comprobó que fuera generalizado a toda la población indígena ni que fuera obligatorio. El subdelegado salió absuelto y ni siquiera fue acusado de realizar actividades comerciales ilícitas en su partido. En esta decisión suponemos que fue muy importante que no hubo queja manifiesta de la población tributaria, la cual supo negociar con la nueva autoridad condiciones más ventajosas.

Una pregunta queda pendiente: ¿mejoraron las condiciones de la población indígena con la supresión del reparto de mercancías y la llegada de los subdelegados? Es difícil generalizar, en el caso que hemos trabajado podría pensarse que mejoraron las condiciones de los tributarios de Carangas, los cuales a partir de la llegada del subdelegado no se vieron obligados a comprar productos innecesarios a precios abusivos como era costumbre en años anteriores con el reparto del corregidor. La disminución de las cargas impositivas podría permitirles más independencia a la hora de conseguir dinero para sus tributos y no tener que verse obligados a emplearse en minas e ingenios, y someterse al maltrato y escasa remuneración. Por supuesto, los efectos no se pueden generalizar porque depende del ejercicio de cada subdelegado. Sería de suponer que el cumplimiento de la ley, la supervisión por parte de las autoridades e instituciones superiores, y el castigo a los infractores deberían garantizar cierta mejoría en las

\footnotetext{
${ }^{95}$ Sergio Serulnikov, "La imaginación política andina”, p. 389.
} 


\section{AMERICANISTAS}

ISSN 1988-7868

\section{María Concepción Gavira Márquez}

El repartimiento de mercancías y los subdelegados en el Alto Perú. La denuncia en 1785 del subdelegado de Carangas, Juan Dionisio Marín. Dossier La vigencia del estudio de los repartimientos en época de subdelegados

condiciones económicas de la población tributaria. ${ }^{96}$ Sin embargo, conocemos otros mecanismos coactivos que se reforzaron para obligar a los indios a trabajar, medidas institucionales y extra-institucionales, como las leyes contra vagos y vagabundos, o los reclutamientos violentos, los pagos del salario en mercancías y el endeudamiento de los trabajadores. Según el análisis de los testimonios de fines del siglo XVIII, en los distritos mineros altoandinos aumentaron las medidas coactivas para hacer trabajar al indio y empeoraron en gran medida las condiciones laborales de los trabajadores mineros. ${ }^{97}$ Es muy posible que esta fuera una respuesta a la supresión del reparto de mercancía entre la población indígena a partir de la llegada de los subdelegados.

\footnotetext{
${ }^{96}$ A veces los intendentes no realizaban la labor de supervisión necesaria de los subdelegados, en la Intendencia de Puno se produjo una situación especial porque el intendente Reseguín permitió el reparto abusivo de algunos de sus subdelegados. David Cahill, "Repartos ilícitos".

${ }^{97}$ Concretamente puede apreciarse en una denuncia de los trabajadores fechada en 1793 de las tres riberas de ingenios de Oruro y Paria, la queja que por su salario le daban una cantidad de mercancías que no necesitaban y a precios abusivos. Los azogueros estaban repartiendo mercancías, no se trataba de las tiendas de "raya" donde el trabajador sacaba productos, era un reparto forzoso a cambio del salario, el cual se reducía considerablemente. Así reclaman: "Digan si es público y notorio el engaño grave y doloso de nuestro personal trabajo y si por el jornal diario y al cabo de una semana nos dan nuestros avíos y socorros en efectos comestibles e inútiles de ropa, recargándonos excesivos precios..." Véase Gavira, Historia de una crisis, p. 221. También sabemos de hacendados que repartían mercancías a cambio de salarios a precios abusivos.
} 